Article

\title{
Study on Solar Power Charging by Flyback Converter
}

\author{
Guo-Shing Huang ${ }^{1}$, Shing-Lih Wu ${ }^{2, *}$, Pei-Siou Ding ${ }^{1}$ \\ 1 Department of Electronic Engineering, National Chin-Yi University of Technology, No.57, Sec.2, \\ Zhongshan Rd., Taiping Dist., Taichung 41170, Taiwan; hgs@ncut.edu.tw (G.-S.H.); \\ dennis22662003@yahoo.com.tw (P.-S.D.) \\ 2 Department of Electrical Engineering, National Taitung Junior College, No.911, Jhengci N. Rd., \\ Taitung 95045, Taiwan \\ * Correspondence: lihchoug@yahoo.com.tw; Tel.: +886-89-226-389; Fax: +886-89-232-871
}

\begin{abstract}
In this paper, a method of charging lead acid battery with solar power by flyback converter is proposed. The basic system consists of a buffer circuit, auxiliary power circuit, control circuit, voltage feedback circuit and current feedback circuit. The system is capable of monitoring battery voltage and the current, charging the coupling inductor and automatic control of output duty cycle, overcharging and over-discharging protection. The experiment proves that the charging efficiency is improved by about $83 \%$ at full load.
\end{abstract}

Keywords: Solar Power; Flyback Converter; Duty Cycle; Coupling Inductor

\section{Introduction}

The resource that Mother Earth can provide is depleting. Oil, the primary source of energy source, is coming to its end of supply. New alternative energy sources have to be found. Among these new energies, solar power features zero pollution. Today, many branches of industries are linked to solar power generation, and batteries are used for energy storage. Among all, lead acid battery is the most commonly used type of battery [1]-[6], as it features stable working voltage and a wide range of working temperature and current. It is capable of charging and recharging for hundreds of cycles, good energy storage performance and low cost [7]-[13]. However, batteries have to be connected in series and parallel for higher voltage and current output to meet the various demands for power. As a result, the safety of the battery during charging becomes increasingly important [13]-[19]. There are a number of studies on battery charging, most of which are focused on pulse charging. The pulse charging works by controlling the length of triggering time with a pulse width modulating controller. When the battery is low, the number of pulses increases, and so does the number of turn-ons at transistor (Q). On the other hand, as the battery is about to be fully charged, both the numbers of pulses and turn-ons at transistor $(\mathrm{Q})$ decrease, so that when the battery is fully charged, the pulse width modulating controller cuts the transistor (Q) off, which completes the charging [20]-[26]. However, this easily leads to overcharging and overheating. In this study, the control circuit, combined with overcharging and over-discharging protection circuits, is capable of balancing the voltage across multiple batteries automatically, while charging multiple batteries and preventing overheating, thus achieving the protection of battery and extended service life of these batteries. The buffer circuit, auxiliary power circuit, control circuit, voltage feedback circuit and 
current feedback circuit is added for better system stability. In addition, the system is able to monitor the battery voltage and the current that charged the coupling inductor, and featured automatic control of output duty cycle and over-charging/discharging protection. The experiment conducts to prove that the system's charging efficiency is improved by about $83 \%$ at full load.

\section{System chart of solar power flyback charger}

The solar power flyback charging system mentioned in this study consisted of a solar panel, control system and lead-acid battery. The system architecture includes coupling inductor, auxiliary power supply, control power supply, over-voltage detection circuit and over-current detection circuit, as shown in Figure 1.

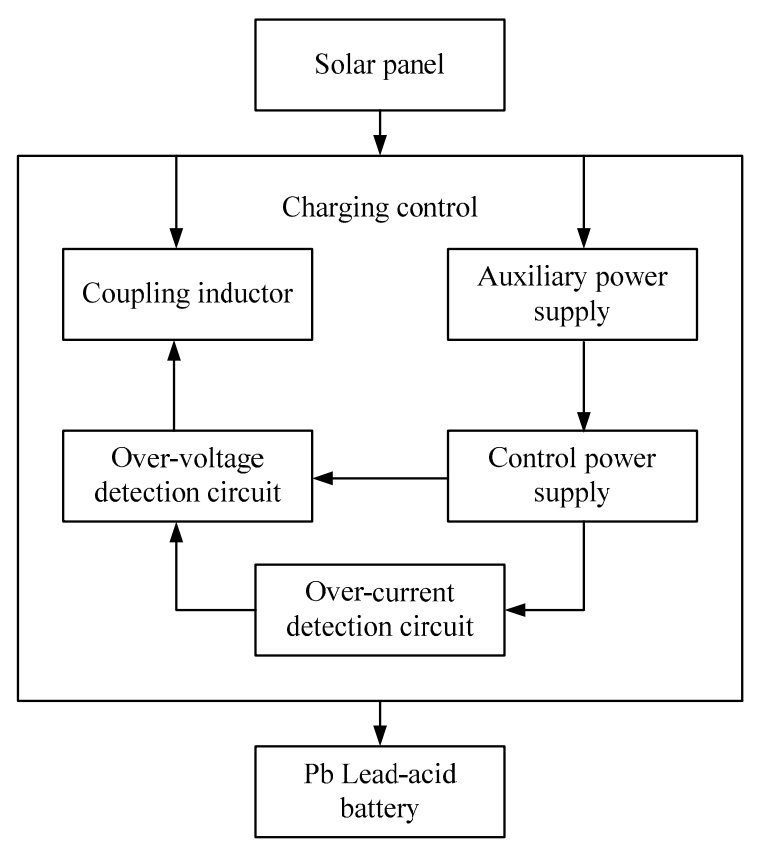

Figure 1 System chart

The flow chart is shown in Figure 2. To start, the solar panel generates $18 \mathrm{~V}$ power which is regulated into controlled by low-ripple voltage via regulating circuit and supplied to pulse width modulating control circuit and DC converter circuit. The control circuit output pulse width is converting into signals for the control of current stored in the inductor. Then, the unstable ripple voltage of secondary output had to control the more stable $12 \mathrm{~V}$ through the output filtering circuit to charge the lead acid battery. The overvoltage and overcurrent protection circuits are used to detect the voltage of battery, and the feedback circuit is used to control the duty cycle of pulse width modulating signals, as shown in Figure 2. 


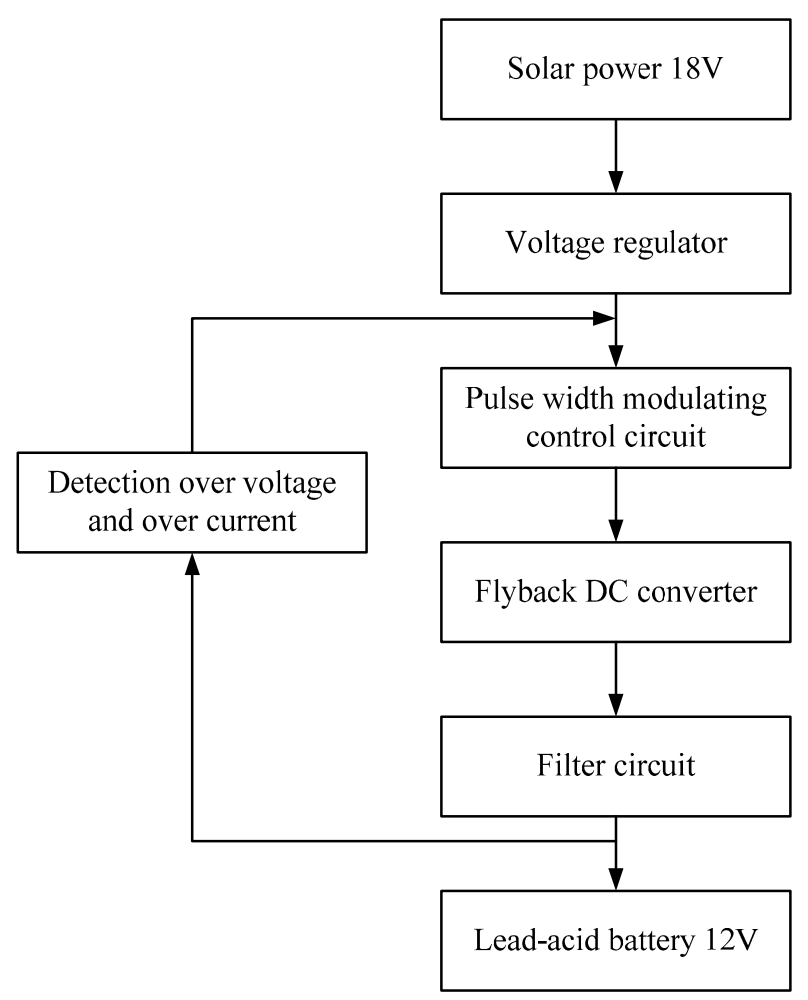

Figure 2 System block diagram

\section{Working principle of system}

\subsection{Buffer circuit design}

Figure 3 shows the buffer circuit. When the transistor is off, the capacitor $\mathrm{C}$ is charged through diode D1 with the voltage on the inductor as its value. When the transistor is turned on, the capacitor discharges along the path of resistor R, the power consumed by the buffer circuit is determined as Eq. (1). Eq. (2) and (3) are used to show the voltage of the capacitor, and Eq. (4) expresses the resistance.

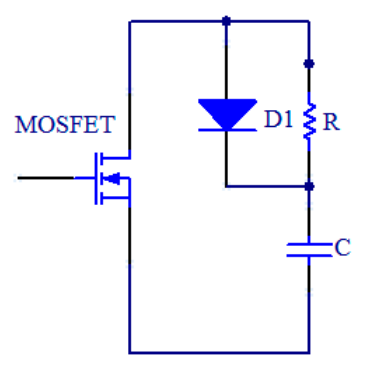

Figure 3 Buffer circuit diagram

$$
\begin{aligned}
& E=\frac{C V_{D S}^{2}}{2}=\frac{I_{D} V_{D S}\left(t_{r}+t_{f}\right)}{2} \\
& C=\frac{I_{D}\left(t_{r}+t_{f}\right)}{V_{D S}} \\
& V_{C}=V_{D S} e^{-\frac{t_{o n}}{R C}}
\end{aligned}
$$


$R=\frac{t_{\text {on }}}{3 C}$

$I_{d i s}=\frac{V_{D S}}{R}$

where $\mathrm{E}$ is energy, $\mathrm{C}$ is the capacitance in the buffer circuit, $V_{D S}$ is the voltage between the drain and source of MOSFET, $V_{C}$ is the voltage of capacitor, $t_{o n}$ is the duration the MOSFET turn on, and Eq.(5) is the discharge current of the buffer circuit.

\subsection{Pulse width regulating control circuit}

The pulse width modulating signal controls the internal circuit of UC3842 and modulates the duty cycle of MOSFET through an external circuit. In this study, the partial voltage of external resistors PIN1 and PIN2 are compared to the internal $2.5 \mathrm{~V}$ by an error amplifier. When the output voltage is greater than $2.5 \mathrm{~V}$, the voltage is too large and therefore, the output duty cycle is reduced. When the output voltage is smaller than $2.5 \mathrm{~V}$, the voltage is too low and therefore, the output duty cycle is increased, as shown in Figure 4. In case that the ideal value and error value are too large, the external compensation circuit PIN1 is conducted to fine-tune the error value and allow the circuit to stay close to the determined ideal value, as shown in Figure 5. The output frequency is determined by the $R_{T}$ of PIN8 and $C_{T}$ of PIN4, as shown in Figure 6 . However, $R_{T}$ has to be greater than $5 \mathrm{k} \Omega$. The frequency is determined with Eq. (6).

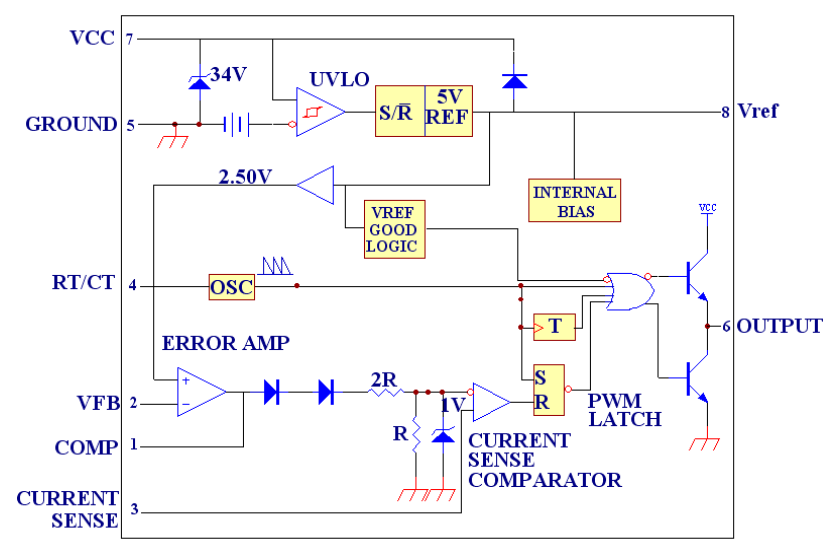

Figure 4 UC3842 block diagram

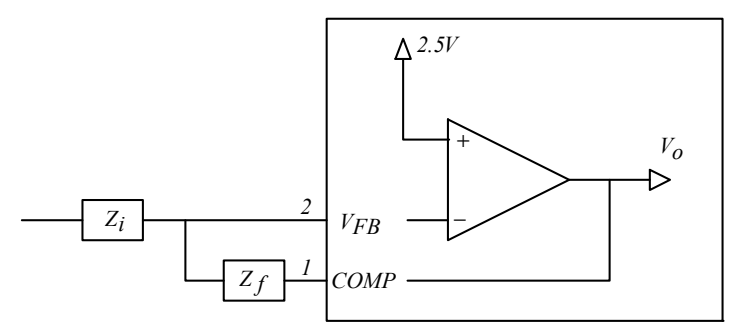

Figure 5 Internal structure of error amplifier in UC3842

$$
\frac{Z_{f}}{Z_{i}}=\frac{V_{o}}{V_{i}}
$$


where $Z_{f}$ is the negative feedback output impedance in $\Omega, Z_{i}$ is the input impedance in $\Omega, V_{o}$ is the output voltage in $\mathrm{V}$, and $V_{i}$ input voltage in $\mathrm{V}$.

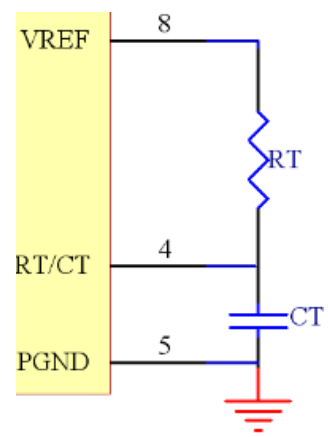

Figure 6 Design frequency circuit diagram

$$
f=\frac{1.72}{R_{T} C_{T}}
$$

where $f$ is the frequency that determines the generated pulse width modulating signals in $\mathrm{Hz}, C_{T}$ is the capacitance that generates oscillation frequency in $\mathrm{F}$, and $R_{T}$ is the resistance that generates oscillation frequency in $\Omega$.

\subsection{System stability design}

As mentioned above, the external compensation circuit PIN1 provides output regulation. There are a variety of feedback compensation techniques available, and the lag compensation circuit is chosen for this study. It proves the improvement of steady state errors, as the lag compensation circuit itself is a type of low-pass filter; such as it only allows low-frequency signals to pass and causes highfrequency signals to attenuate. In this study, a pair of zero-pole operational amplifier circuit is designed. The feedback is used to fix the system within a frequency range without any phase shift.

Table I Stability design parameters

\begin{tabular}{|c|c|}
\hline Electronic component & Value \\
\hline$R_{1}$ & $4 \mathrm{k} \Omega$ \\
\hline$R_{3}$ & $400 \mathrm{k} \Omega$ \\
\hline$C_{1}$ & $2 \mathrm{pF}$ \\
\hline$C_{2}$ & $8 \mathrm{pF}$ \\
\hline
\end{tabular}

As shown in Table I, the crossover frequency is set at $f_{c}=10 \mathrm{kHz}$, since the pulse width modulating signal frequency is $f=100 \mathrm{kHz}$. The crossover frequency is designed as $10 \%$ of the pulse width modulating signal frequency for a more stable system. Then, the zero frequency is defined as $f_{1}=2 \mathrm{kHz}$, pole frequency as $f_{2}=50 \mathrm{kHz}$, voltage gain as $\mathrm{AV}=100$ and $R_{3}=400 \mathrm{k} \Omega$. By substituting $A V$ and $R_{3}$ into Eq. (8), it is determined that $R_{1}=4 \mathrm{k} \Omega$. By substituting $R_{3}$ and $f_{1}$ into Eq. (9), it is determined that $C_{1}=2 \mathrm{pF}$. Then by substituting $f_{2}, C_{1}$ and $R_{3}$ into Eq. (10), $C_{2}=8 \mathrm{pF}$ is determined. 


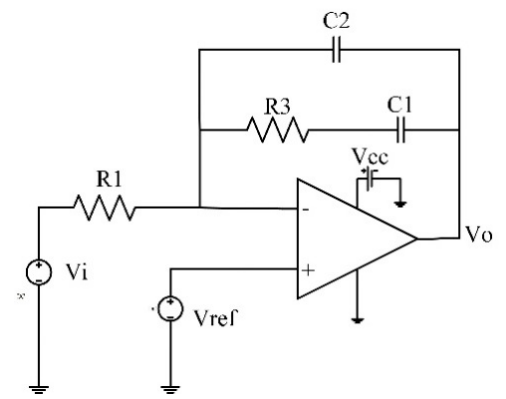

Figure 7 Circuit diagram of system stability design

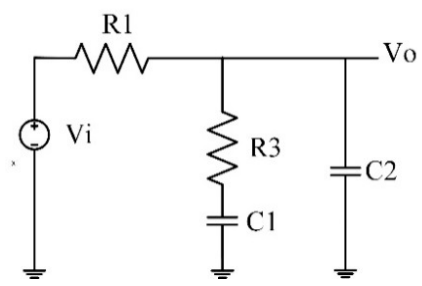

Figure 8 Circuit diagram of low-pass filter

$\frac{R_{3}}{R_{1}}=A V$

$\frac{1}{2 \pi \times R_{3} \times C_{1}}=f_{1}$

$\frac{C_{1}+C_{2}}{2 \pi \times R_{3} \times C_{1} \times C_{2}}=f_{2}$

where $R_{3}$ is the negative feedback resistance in $\Omega, R_{l}$ is the input resistance in $\Omega, A V$ is the voltage gain, and $C_{1}, C_{2}$ are the capacitances that determine the frequency response in $\mathrm{F}$.

\subsection{Winding of coupling inductor}

The winding of coupling inductor is aimed to turn ratio and the size of used enameled wire. For a flyback converter, the wire is wound in the reverse direction. As the inductor reached volt-sec balance, the turn ratio $\mathrm{n}$ is determined by substituting $V_{i n, \min }, V_{o}, V_{f}$ and $D_{\max }$ (Duty Cycle) into Eq. (11). For safety reason, the $D_{\max }$ is designed at approximately $40 \%$. For the size of the used enameled wire of windings, Eq. (14)-(18) are used to determine the radius of the wire for the inductor windings. Using Eq. (19), the volume of coupling inductor is determined and substituted into Eq. (20) and (21) to determine the number of windings at the primary and secondary sides. The iron core used in this study is EE30. The $B_{m}$ value is substituted into the range of $1500 G_{\text {uess }}$ empirically.

$\frac{V i_{\min } \times D_{\max }}{\left(V_{o}+V_{f}\right)\left(1-D_{\max }\right)}=n$ 
where $V_{i n, \min }$ is the minimum of initial voltage imposed in $\mathrm{V}, D_{\max }$ is the maximum duty cycle in \%, $V_{o}$ is output voltage in $\mathrm{V}, V_{f}$ is the different voltage across the diode in $\mathrm{V}$, and $\mathrm{n}$ is the turn ratio between primary and secondary windings in turns.

$\frac{P_{i}}{V_{i}}=I_{i}$

$P_{i}$ is the input power in $\mathrm{W}$ and $V_{i}$ is the input voltage in $\mathrm{V}$.

$\frac{P_{o}}{V_{o}}=I_{o}$

$P_{o}$ is output power in $\mathrm{W}, I_{i}$ is input current in A, and $I_{o}$ is output current in A.

$$
\begin{aligned}
& \frac{3.13 \times P_{o}}{V_{\text {in,max }}}=I_{p} \\
& \frac{I_{s}}{I_{p}}=n
\end{aligned}
$$

$V_{\text {in,max }}$ is the maximum initial voltage imposed in $\mathrm{V}, I_{p}$ is the primary side current in $\mathrm{A}, I_{s}$ is the secondary side current in $\mathrm{A}$, and $\mathrm{n}$ is the turn ratio between primary and secondary windings in turns.

$4 \pi r^{2}=I$

$\sqrt{\frac{I_{p}}{4 \times \pi}}=r_{p}$

$\sqrt{\frac{I_{s}}{4 \times \pi}}=r_{s}$

$r_{p}$ is the wire radius at the primary side in $\mathrm{mm}$ and $r_{s}$ is the wire radius at the secondary side in mm.

$\frac{P_{o} \times 10^{9}}{1.16 \times B_{\max } \times f}=A_{e} \times A_{c}$

$\frac{V_{i n, \max } \times 10^{8}}{4 f B_{\max } \times A_{e}}=N_{p}$

$\frac{N_{p}}{n}=N_{s}$ 


\section{Experiment}

The waveform of inductor and current are measured and efficiency of those are compared. Modification is made based on experiment results and the optimized value is obtained. The measurement flowchart is provided in Figure 9.

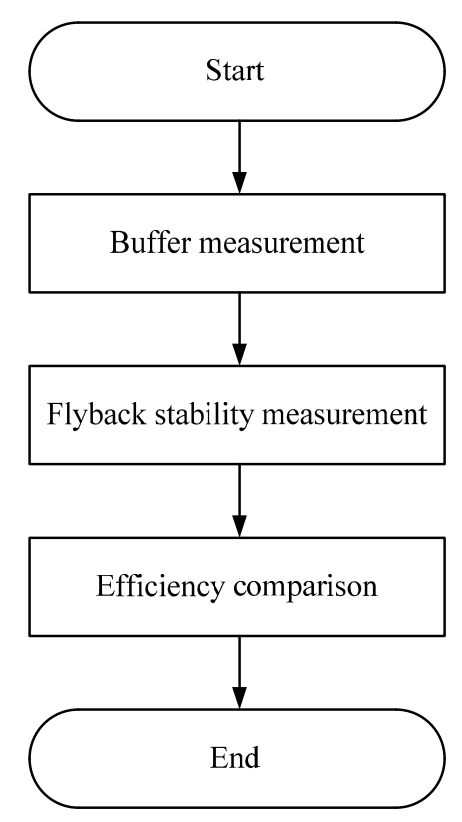

Figure 9 Measurement flowchart

\subsection{Waveform measurement}

The $V_{D S}$ of MOSFET is measured for waveforms. A comparison is made between the presence and absence of buffer. The input voltage and load were varied for measurement.

\subsection{Efficiency comparison}

The voltage measurements yielded the input and output powers, which were used to calculate the conversion efficiency. The experiment result suggests the impact of increase and decrease of input voltage on the conversion efficiency.

\section{Experiment results}

It is clear in Figure 10 that the conversion efficiency of the solar panel was at its highest between 10:00 am and 3:30 pm. Shading caused decrease of conversion efficiency in this period of time. The feedback circuit is designed to change the magnitude and increase the stability of power supply. With a load of $100 \Omega$, the input voltage is $18 \mathrm{~V}$ and output voltage is $13.3 \mathrm{~V}$, as shown in Figure 13 . The idea to add a buffer circuit in the system is to avoid damage of elements due to instability of input voltage or even unwanted oscillations. These oscillations led to very high voltage at the $V_{D S}$ end. The $18 \mathrm{~V}$ input can increase the oscillation voltage up to $80 \mathrm{~V}$ as shown in Figure 11 . However, the addition of buffer circuit reduced the oscillation voltage significantly, as the voltage amplitude dropped from $80 \mathrm{~V}$ to $20 \mathrm{~V}$. This demonstrates effective reduction of power loss on MOSFET and in turn the protection of MOSFET, as shown in Figure 12. 


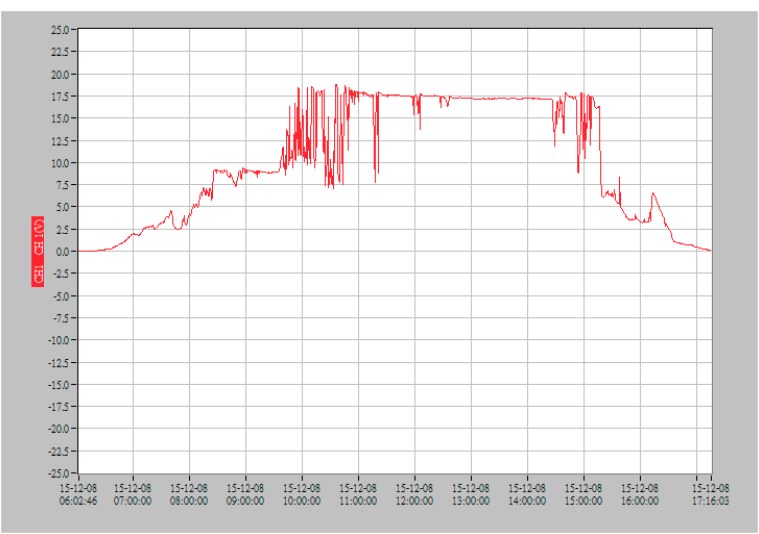

Figure 10 Voltage waveform of solar panel

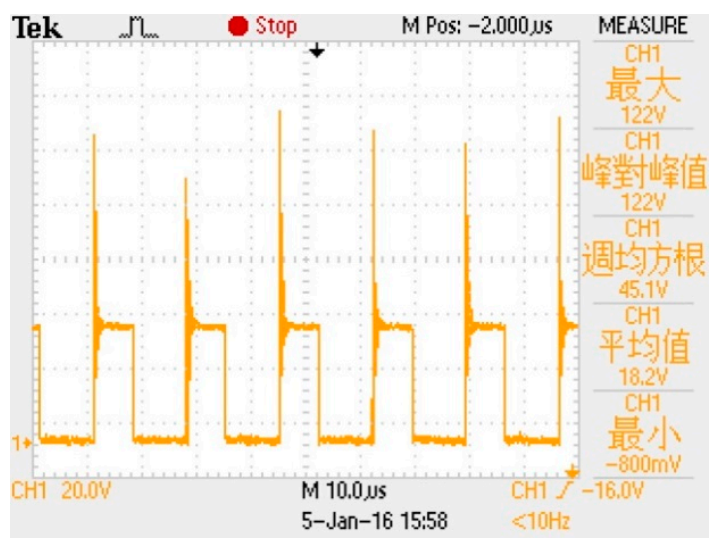

Figure $11 V_{D S}$ without buffer

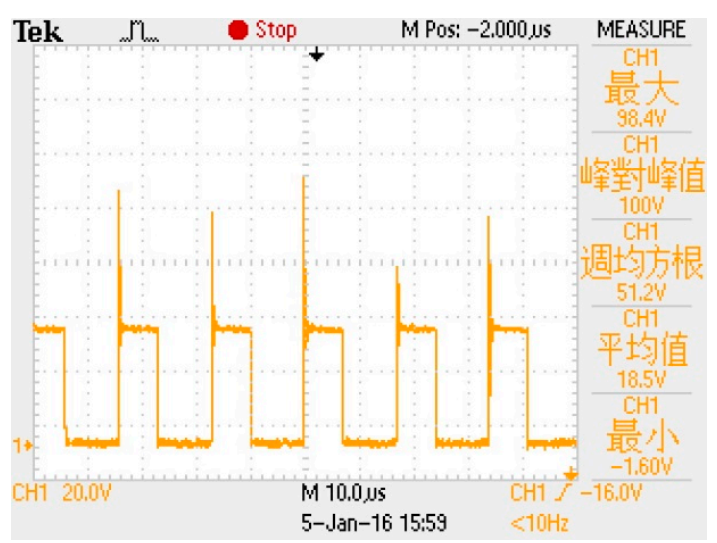

Figure $12 V_{D S}$ with buffer

The stability of power supply is improved by regulating the magnitude of duty with the feedback circuit designed. With a load of $100 \Omega$, the input voltage is $18.2 \mathrm{~V}$, the output voltage is $13.3 \mathrm{~V}$ and the duty is $21 \%$, as shown in Figure 13 . With a load of $10 \Omega$, the input voltage is $17.8 \mathrm{~V}$, the output voltage is $12.9 \mathrm{~V}$, and the duty is $43 \%$, as shown in Figure 14. 


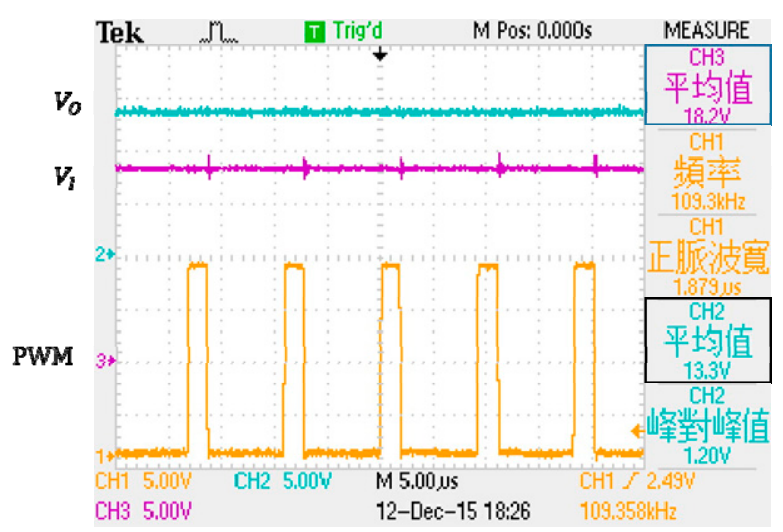

Figure 13 With a load of $100 \Omega$

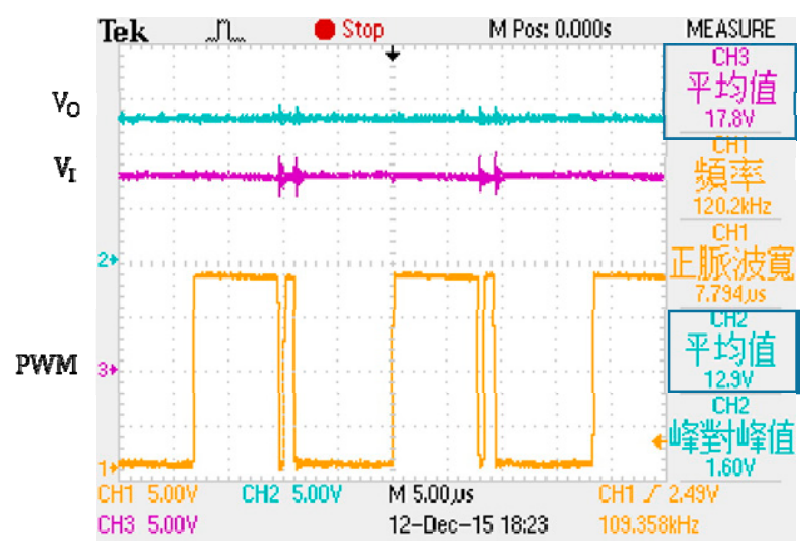

Figure 14 With a load of $10 \Omega$

As indicated in Table II, the output power reaches as high as $16.6 \mathrm{~W}$ at the same voltage by only changing the loading. Due to the addition of feedback circuit, the larger the load, the greater the duty cycle; whereas the smaller the load, the smaller the duty cycle.

Table II Load and duty cycle

\begin{tabular}{|c|c|c|c|c|c|c|}
\hline$V_{D S}$ & $18 \mathrm{~V}$ & $18 \mathrm{~V}$ & $18 \mathrm{~V}$ & $18 \mathrm{~V}$ & $18 \mathrm{~V}$ & $18 \mathrm{~V}$ \\
\hline Duty $(\%)$ & 11.3 & 12.8 & 20.8 & 27.6 & 29.8 & 43.3 \\
\hline$V_{O}(\mathrm{~V})$ & 13.3 & 13.3 & 13.3 & 13.2 & 13.1 & 12.9 \\
\hline$P_{O}(\mathrm{~W})$ & $3.5 \mathrm{~m}$ & $215 \mathrm{~m}$ & 1.77 & 3.48 & 8.58 & 16.6 \\
\hline $\operatorname{Load}(\Omega)$ & $50 \mathrm{k}$ & 820 & 100 & 50 & 20 & 10 \\
\hline
\end{tabular}

When the input voltage is $14.1 \mathrm{~V}$, the output voltage is $12 \mathrm{~V}$, the load is $10 \Omega$ and the duty cycle is $43 \%$, as shown in Figure 15. When the input voltage is $18.1 \mathrm{~V}$, the output voltage is $13 \mathrm{~V}$, the load is $10 \Omega$ and the duty cycle is $43 \%$, as shown in Figure 16. It is found that the output voltage dropped by $1 \mathrm{~V}$ and the duty cycle remained the same when the output voltage decreased from 18.1 to $14.1 \mathrm{~V}$. PWM decreased with the input voltage. 


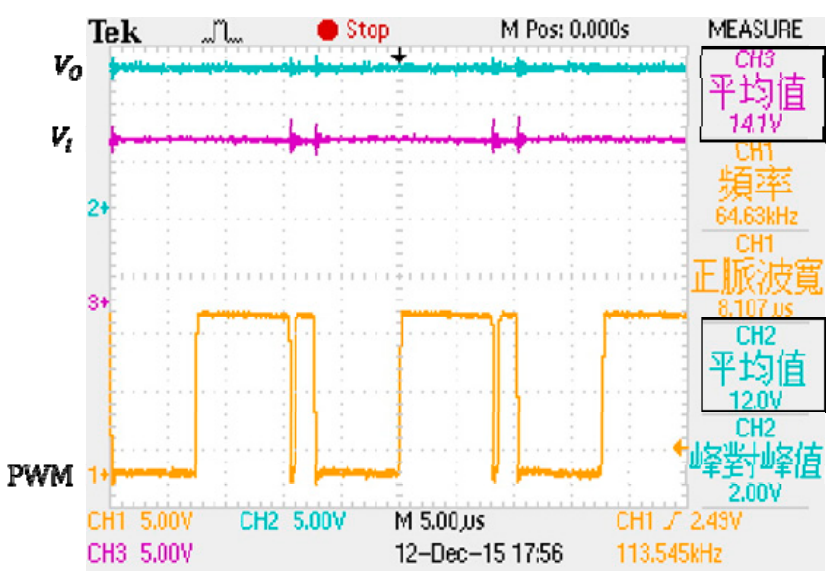

Figure 15 With an input of $14 \mathrm{~V}$

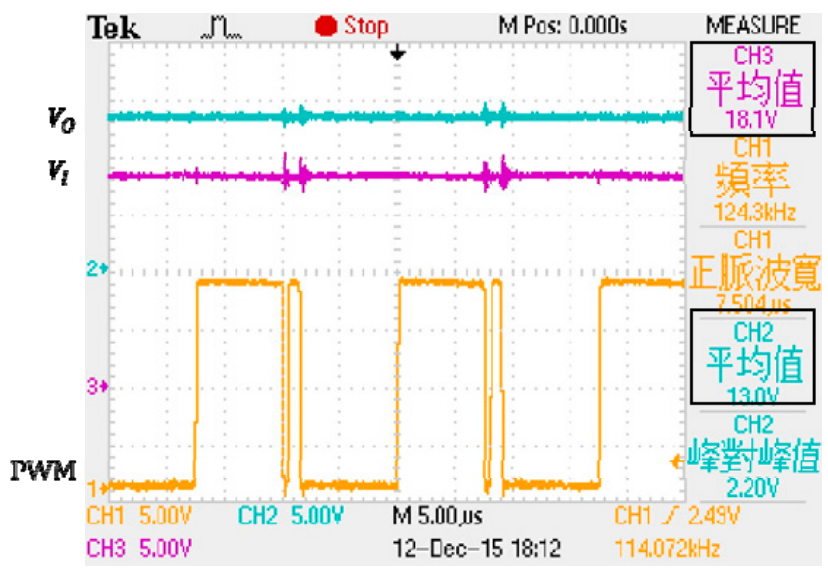

Figure 16 With an input of $18 \mathrm{~V}$

It is clear in Table III that the efficiency decreased with the input voltage as the battery is being charged. The reason is the power loss due to the internal resistance of MOSFET $r_{D S}$ and leakage inductance. The leakage inductance loss increased as the input voltage is close to the output voltage. It becomes difficult to drive the MOSFET when the PWM voltage is decreased, and the internal resistance $r_{D S}$ is increased, which causes power loss.

Table III Input voltage vs efficiency

\begin{tabular}{|c|c|c|c|c|c|c|}
\hline$V_{I}(\mathrm{~V})$ & $I_{I}(\mathrm{~A})$ & $P_{I}(\mathrm{~W})$ & $V_{O}(\mathrm{~V})$ & $I_{O}(\mathrm{~A})$ & $P_{O}(\mathrm{~W})$ & $\eta(\%)$ \\
\hline 10.5 & 2.04 & 21.42 & 10.4 & 1.04 & 10.82 & 50.51 \\
\hline 11 & 2.08 & 22.88 & 10.5 & 1.05 & 11.03 & 48.21 \\
\hline 12 & 1.86 & 22.32 & 11.7 & 1.17 & 13.69 & 61.34 \\
\hline 13 & 1.72 & 22.36 & 11.9 & 1.19 & 14.16 & 63.33 \\
\hline 14 & 1.63 & 22.82 & 12 & 1.2 & 14.4 & 63.1 \\
\hline 15 & 1.52 & 22.8 & 12.2 & 1.22 & 15.13 & 66.36 \\
\hline 16 & 1.35 & 21.7 & 12.6 & 1.26 & 15.88 & 73.17 \\
\hline 17 & 1.26 & 21.42 & 12.8 & 1.28 & 16.38 & 76.47 \\
\hline 18 & 1.13 & 20.34 & 13 & 1.3 & 16.9 & 83.10 \\
\hline
\end{tabular}


The solar power battery chargers available in the market sometimes experience unstable current. As indicated in Figure 17, it is clear that a current up to $4 \mathrm{~A}$ is generated when the PWM switch is turned on and off. When a lead acid battery is charged under such a maximum instantaneous current, the battery's service life is reduced as the charging time increases. The output voltage provided by the design presented in this study is much more stable than that by market-available products for lead acid battery charging. The maximum instantaneous current generated is smaller when the PWM is switched on and off as indicated in Figure 18.

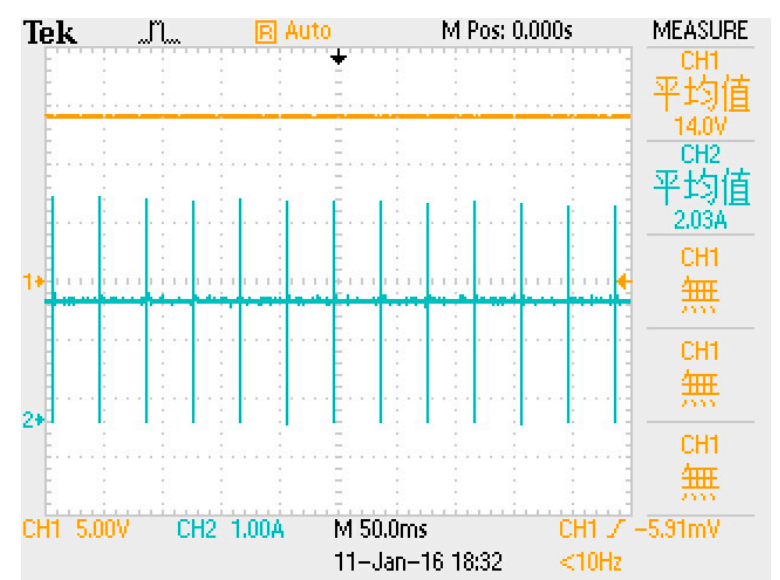

Figure 17 Output voltage and current of market available solar panel

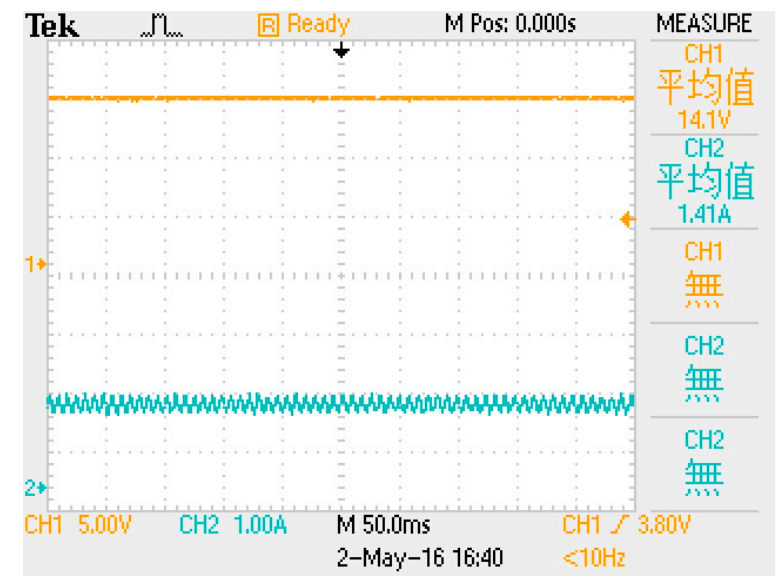

Figure 18 Output voltage and current of the paper available solar panel

\section{Conclusion}

This study is motivated by the instability of solar power generation. A flyback charged is used to convert sunlight into electric energy to store in lead acid battery. Over-charge/discharging protection is added to detect the battery charging. The experiment results suggest $6.6 \%$ of error between the ideal value and practical value. The design presented in this study is capable of fast charging with the standard test condition of the sunshine intensity of $1000 \mathrm{~W} / \mathrm{m}^{2}$. The design is capable of monitoring the battery charging, thus contributing to the longevity of battery. In addition, the unstable current output commonly seen in market-available products is improved.

\section{References}


1. Hua, and B. Syue, "Charge and Discharge Characteristics of Lead-acid Battery and LiFePO4 Battery," IEEE Power Electronics Conference, pp.1478 - 1483, June 2010.

2. W. Jian, X. Jiang, J. Zhang, and Y. Chen, "Recursive Adaptive Parameters Estimation for LiFePO4 Battery Model," IEEE Computational and Information Sciences, pp.1138-1141, June 2013.

3. Y. Yang, and H. Li, "Performance Analysis of LiFePO4 Battery Energy Storage for Utility-scale PV System," IEEE Energy Conversion Congress and Exposition, pp.414-419, Sept. 2014.

4. M. Zhao, J. Long, Y. Chen, B. Luo and J. Liu, "Surplus electric quantity online examination system of Lead-acid battery based on ARM," IEEE 2008 World Automation Congress, pp.1-4, Oct. 2008.

5. D. Kim and H. Cha, "Kt Factor analysis of lead-acid battery for nuclear power plant," IEEE Electrical Machines and Systems, pp526-529, Oct. 2013.

6. M. Eifert, "A discrete battery state monitoring algorithm for lead-acid batteries," 2014 IEEE Conference on Control Applications, pp1119-1126, Oct. 2014.

7. M Lai, M. J Yang and W. C Liu, "Parallel-operated single-stage flyback-type single-phase solar micro-inverter," IEEE Intelligent Green Building and Smart Grid, pp1-5, April 2014.

8. M. I. M. Montero *, J. G. Lozano, E. R. Cadaval and E. G.Romera," Hall-Effect Based Semi-Fast AC On-Board Charging Equipment for Electric Vehicles”, Sensors, p.p. 9313-9326, Nov. 2011.

9. Y. T Chen and S. Y Wei, "A multiple-winding bidirectional flyback converter used in the solar system," IEEE Next-Generation Electronics, pp130-133, Feb. 2013.

10. M. A Rezaei, K. J Lee and A. Q. Huang, "A high efficiency flyback micro-inverter with a new adaptive snubber for photovoltaic applications," IEEE Energy Conversion Congress and Exposition, pp3308-3313, Sept. 2015,

11. H. Osuga, I. Terukina and H. Nagano, "A Study of High Voltage Converter Topologies with Wide Input Voltage Range,” IEEE Telecommunication - Energy Special Conference, pp.1-8, May 2009.

12. Y. Choi, M. H Keum, S. K Han and J. I Kang, "High efficiency and high power factor singlestage balanced forward-flyback converter," IEEE Industrial Electronics Society, pp.822-827, Nov. 2013.

13. R. C V. and R. G. "Voltage mode control of improved bridgeless flyback rectifier with bidirectional switch for adapter applications" IEEE Electrical, Electronics, Signals, Communication and Optimization, pp1-6, Jan. 2015.

14. J. Umuhoza, Y. Zhang, Y. Liu, J. Moquin, C. Farnell and H. A Mantooth, "Interleaved Flyback based micro-inverter for residential photovoltaic application in remote areas," IEEE Workshop on Control and Modeling for Power Electronics, pp1-6, July 2015.

15. H. Dong, X. Xie, K. Peng, J. Li and C. Zhao, "A variable-frequency one-cycle control for BCM flyback converter to achieve unit power factor," IECON 2014 - 40th Annual Conference of the IEEE Industrial Electronics Society, pp1161-1166, Nov. 2014.

16. M. Su, W. Chen, MiDong and R. Yang, "Simulation research of boost-flyback photovoltaic gridconnected micro-inverter," IEEE Chinese Automation Congress, pp2135-2139, Nov. 2015.

17. L. An and D. Lu, "Design of a Single-switch DC-DC Converter for PV-battery Powered Pump System," IEEE Future Energy Electronics Conference, pp.359-364, Nov. 2013. 
18. A. Husna, S. Siraj, and M. Z. A. Muin, "Modeling of DC-DC Converter for Solar Energy System Applications," IEEE Computers \& Informatics, pp.125-129, March 2012.

19. K. Edelmoser, and F. Himmelstoss, "DC-to-DC Solar Converter with Controlled Active Clamping System," IEEE Power Electronics and Motion Control Conference, pp.124-127, Sept. 2006.

20. K. Kishorem, N. Brahmendra, P. So, and C. Chan, "A PWM Soft Switched DC-DC Converter for PV and EV," IEEE Photovoltaic Specialist Conference, pp.3707-3712, 2014.

21. L. Li, L. Wang, C. Lv, and C. Sun, "A Simulation of Conducted EMI in Flyback Converters," IEEE Power Electronics and Motion Control Conference, pp.1794-1798, June 2012.

22. M. R Yazdani, H. Farzanehfard, and J. Faiz, "EMI Analysis and Evaluation of an Improved ZCT Flyback Converter," IEEE Power Electronics, pp.2326-2334, Aug. 2011.

23. Y. Lo, and J. Lin, "Active-Clamping ZVS Flyback Converter Employing Two Transformers," IEEE Power Electronics, pp.2416-2423, Sept. 2007.

24. S. Li, C. Zhang, S. Xie, "Research on Fast Charge Method for Lead-Acid Electric Vehicle Batteries," IEEE Intelligent Systems and Applications, pp.1-5, May 2009.

25. G. Yifeng, and Z. Chengning, "Study on the Fast Charging Method of Lead-acid Battery with Negative Pulse Discharge," IEEE Power Electronics Systems and Applications, pp.1-4, June 2011.

26. S. G. Abeyratne, P. S. N. Perera, H. S. Jayakody, S. M. K. B. Samarakoon, and R. R. S. De Bulathge, "Soft Switching Fast Charger for Batteries Used in Renewable Energy Applications and Electric Vehicles," IEEE Industrial and Information Systems, pp.1-6, Aug. 2012. 